\title{
Role of bone scintigraphy in the early diagnosis of discitis*
}

\author{
K Choong, P Monaghan, L McGuigan, R McLean
}

\begin{abstract}
Nine cases of recorded discitis are presented, in which scintigraphy played an important part in the diagnosis. The patients (five men (aged 21-75 years) and four women (aged 40-73 years)) had a history of back pain varying in duration from two days to three months. Final diagnosis was confirmed microbiologically (seven patients) or radiographically (two patients). Bone scintigraphy was a valuable diagnostic procedure for discitis with earlier detection than plain radiography in three patients and similar initial detection to that of third generation computed tomography. Single photon emission computed tomographic imaging increased diagnostic confidence by indicating the involvement of the adjacent vertebral bodies rather than of the pedicles or spinous processes.
\end{abstract}

Discitis is an inflammatory disorder affecting the intervertebral disc, often following an invasive procedure but in some cases, arising anew. The clinical features, comprising fever, back pain, and constitutional symptoms, are not specific for discitis. Both radiographic and microbiological criteria have been used to establish the diagnosis of discitis, ${ }^{12}$ but these criteria may not be present early in the disorder.

Over the past two decades several case reports and reviews have suggested a place for scintigraphy in the detection or confirmation of discitis. ${ }^{1}{ }^{3} 4$ We present a cohort of nine patients with proved discitis, and review the role of scintigraphy in the early diagnosis of this condition.
Patients and methods

Nine consecutive patients with discitis proved over the preceding three years were reviewed. The clinical details were obtained from the patients' files. Most patients had had sequential scintigraphic and radiographic studies. All scans and radiographs were reviewed at the time of the study, but only the original reports were used to provide data for this study.

Bone scintigraphy was performed with technetium-99m methylene diphosphonate $(\sim 11 \mathrm{MBq} / \mathrm{kg})$ using a large field of view gammacamera. Blood pool images of the region under study were obtained immediately after administration of the radiopharmaceutical and a regional or whole body bone scan performed two to three hours later, together with single photon emission computed tomography (SPECT) imaging in eight of the nine patients. The scintigraphic criteria for discitis were increased uptake in the vertebral bodies on either side of the affected disc space together with increased blood pool activity (figs $1 \mathrm{~A}$ and B).

Computed tomographic (CT) scanning was performed with a third generation scanner. The criterion used for the diagnosis of discitis was the destruction of the vertebral end-plates adjacent to the disc space (fig 2), and the plain radiographic criteria used were disc space narrowing, subchondral sclerosis, and irregular erosion of the vertebral end-plates adjacent to the disc space (fig 3).

The sequencing of and the time interval between radiography, CT scanning, and scintigraphy varied between patients.
Departments of Nuclear Medicine and Rheumatology, St George Hospital, Kogarah, NSW, Australia

$\mathrm{K}$ Choong

$P$ Monaghan

L McGuigan

R McLean

Correspondence to:

Dr K Choong,

c/o Department of Nuclear

Medicine and Ultrasound

Westmead Hospital,

Westmead 2145, Sydney, Australia.

Accepted for publication 28 December 1989

*Presented at the Annual Scientific Meeting of the Australian and New Zealand Society of Nuclear Medicine, Christchurch, New Zealand. August 1989.

\begin{tabular}{|c|c|c|c|c|c|c|c|}
\hline \multirow[t]{2}{*}{$\begin{array}{l}\text { Case } \\
\text { No }\end{array}$} & \multirow[t]{2}{*}{$\begin{array}{l}\text { Age } \\
\text { (years) }\end{array}$} & \multirow[t]{2}{*}{$\begin{array}{l}\text { Disc } \\
\text { level }\end{array}$} & \multirow[t]{2}{*}{ Microbiology } & \multicolumn{3}{|c|}{$\begin{array}{l}\text { Investigation results }{ }^{*} t \\
\text { (symptom duration in weeks) }\end{array}$} & \multirow[t]{2}{*}{$\begin{array}{l}\text { Predisposing } \\
\text { factors }\end{array}$} \\
\hline & & & & Radiograph & $\begin{array}{l}\text { CTt } \\
\text { scan }\end{array}$ & $\begin{array}{l}\text { Bone } \\
\text { scan }\end{array}$ & \\
\hline 1 & 40 & T11/12 & $\begin{array}{l}\text { Negative } \\
\text { (incl. disc) }\end{array}$ & $\begin{array}{l}+ \\
(4 \cdot 5)\end{array}$ & $\overline{-}($ at 1 wk) & $\begin{array}{l}+ \\
(3)\end{array}$ & Recent cone biopsy:cervix \\
\hline 2 & 52 & $\mathbf{L} 5 / \mathrm{S} 1$ & $\begin{array}{l}\text { Staph aureus } \\
\text { (blood/disc) }\end{array}$ & $\begin{array}{l}(+7) \\
+ \\
(12 \cdot 5)\end{array}$ & $\begin{array}{l}+ \\
+(12 \cdot 5)\end{array}$ & $\stackrel{+}{+}$ & Recent discography \\
\hline 3 & 73 & $\mathrm{~T} 12 / \mathrm{Ll}$ & $\begin{array}{l}\text { Staph aureus (blood } \\
\text { only)-No disc biopsy }\end{array}$ & $\begin{array}{l}(120) \\
+ \\
(7)\end{array}$ & $\begin{array}{l}+ \\
(7)\end{array}$ & $\begin{array}{l}\text { Equiv } \\
(7) \ddagger\end{array}$ & $\begin{array}{l}\text { Diverticular disease. } \\
\text { Staph septicaemia }\end{array}$ \\
\hline 4 & 61 & L5/S1 & $\begin{array}{l}\text { Staph aureus (blood } \\
\text { only)-No disc biopsy }\end{array}$ & $\begin{array}{l}+ \\
(1 \cdot 5)\end{array}$ & $\begin{array}{l}\text { Equiv } \\
\text { (1) }\end{array}$ & $\begin{array}{l}+ \\
(1)\end{array}$ & $\begin{array}{l}\text { Recent coronary } \\
\text { angioplasty }\end{array}$ \\
\hline 5 & 72 & $\mathrm{Ll} / 2$ & Staph aureus (disc only) & + & NP & $\begin{array}{l}+ \\
(12)\end{array}$ & $\begin{array}{l}\text { Aortic aneurysm repair. } \\
\text { Chronic renal failure }\end{array}$ \\
\hline 6 & 59 & $\mathrm{~L} 4 / 5$ & $\begin{array}{l}\text { Staph aureus (blood } \\
\text { only)-No disc biopsy }\end{array}$ & $\stackrel{+}{+}$ & $\begin{array}{l}+ \\
(3)\end{array}$ & $\begin{array}{l}+ \\
(3)\end{array}$ & $\begin{array}{l}\text { Recent epidural steroid } \\
\text { injection }\end{array}$ \\
\hline 7 & 21 & $\mathrm{~L} 5 / \mathrm{S} 1$ & $\begin{array}{l}\text { Negative (No disc } \\
\text { biopsy) }\end{array}$ & $\begin{array}{l}+ \\
(4)\end{array}$ & $\begin{array}{l}+ \\
(4)\end{array}$ & $\begin{array}{l}+ \\
(4)\end{array}$ & Absent \\
\hline 8 & 75 & $\mathrm{~L} 3 / 4$ & $\begin{array}{l}E \text { Coli (urine/blood) } \\
\text {-No disc biopsy }\end{array}$ & $\stackrel{+}{+}$ & $\stackrel{+}{+}$ & $\stackrel{+}{+}$ & Absent \\
\hline 9 & 21 & L3/4 & $\begin{array}{l}\text { Staph aureus (disc } \\
\text { biopsy) }\end{array}$ & $\stackrel{+}{(11 \cdot 5)}$ & NP & $\stackrel{+}{+}$ & Absent \\
\hline
\end{tabular}

*The sequencing of and the time interval between imaging modalities varied between patients.

The sequencing of and the time interval between imaging modalities varied between patients. $t+=$ discitis present; $-=d$
$\ddagger=$ SPECT not performed. 


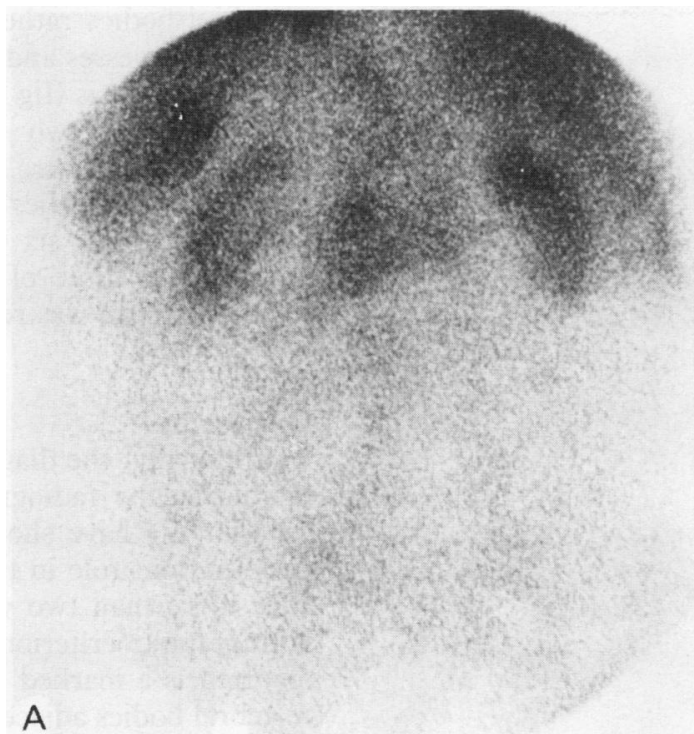

Figure 1 Bone scintigraphic scan showing increased uptake of technetium- $99 \mathrm{~m}$ methylene diphosphonate in the vertebral bodies on either side of the affected disc space $(B)$ with increased vascularity on the blood pool image $(A)$.

\section{Results}

The clinical data and results of investigations are shown in the table.

All nine patients were adults with fever and back pain. The erythrocyte sedimentation rate was raised in all patients. The disc level affected varied between T11/12 and L5/S1.

Discitis was confirmed by microbiology in seven cases; Staphylococcus aureus was the causative organism in six. In two cases the microbiology tests were negative, but progress radiographs showed changes characteristic of discitis and the clinical course was consistent with this diagnosis.

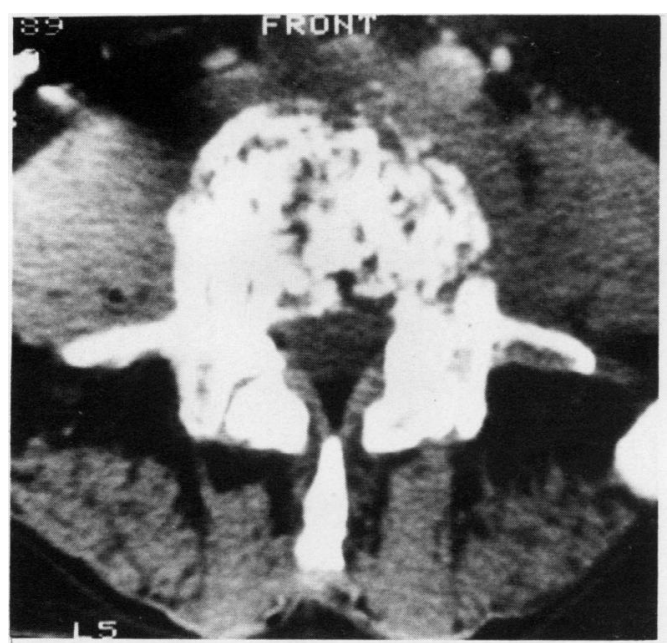

Figure 2 Computed tomographic scan showing destruction of the vertebral end plates adjacent to the disc space.
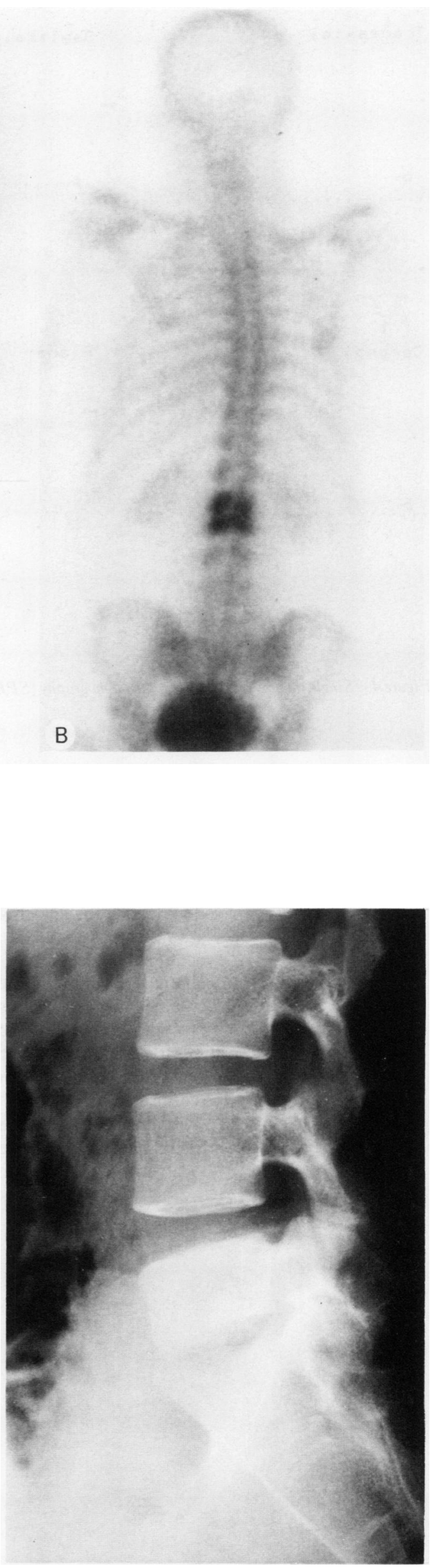

Figure 3 Plain radiograph showing disc space narrowing, subchondral sclerosis, and irregular erosion of the vertebral end plates adjacent to the disc space. 


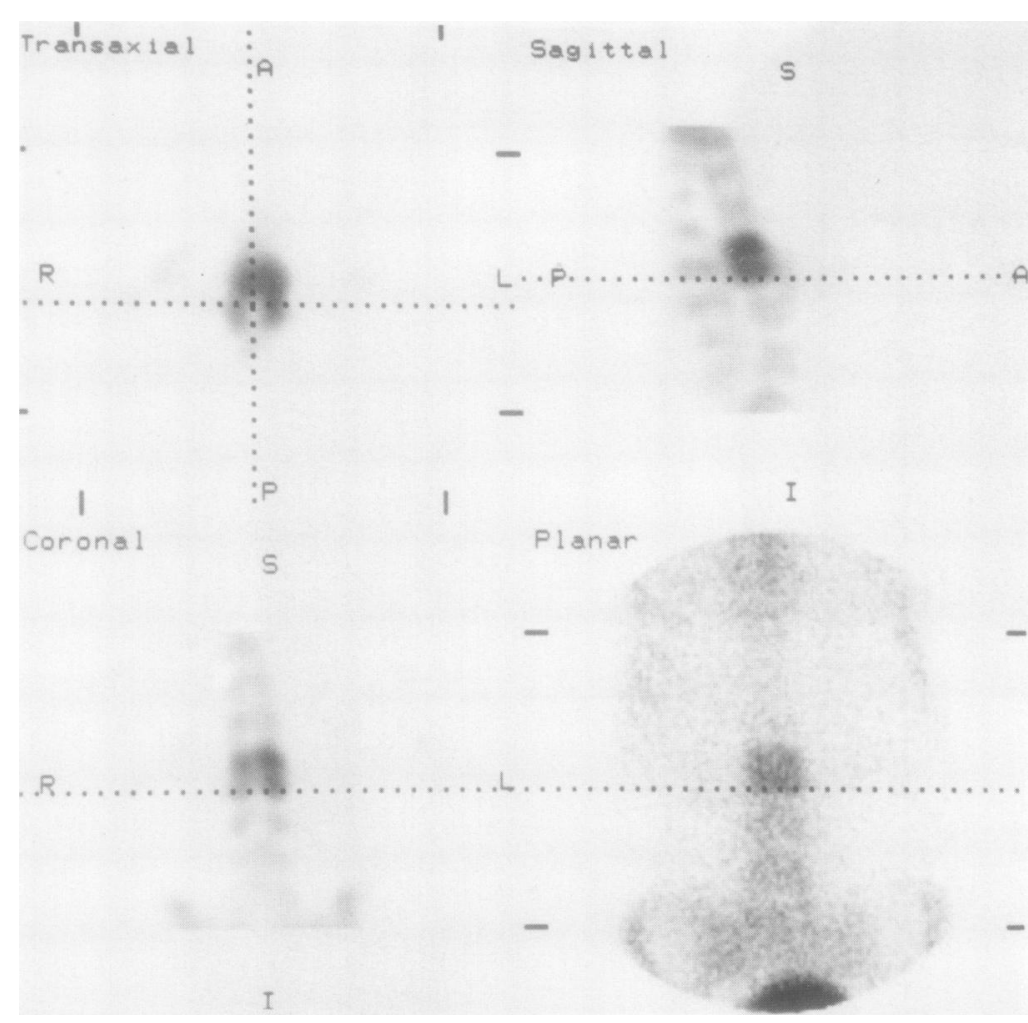

Figure 4 Single photon emission computed tomography (SPECT) image.

In those patients who had scintigraphic and radiological investigations performed within a week of one another the following results were found: $(a)$ scintigraphic changes clearly antedated plain radiographic changes in three patients; $(b)$ in one patient scintigraphy was diagnostic for discitis while concurrent CT scanning was equivocal; $(c)$ scintigraphic changes occurred concurrently with plain radiographic changes in three patients, and with CT scan changes in two patients; $(d)$ in one patient plain radiography and CT scanning were positive for discitis while bone scintigraphy was equivocal. Incidentally, concurrent gallium-67 citrate scanning was positive.

In the eight patients who had additional SPECT imaging this technique was valuable in localising the planar image abnormalities to the vertebral bodies rather than to the pedicles or spinous processes and thereby further supporting the diagnosis (fig 4).

In the first two weeks of symptoms no diagnostic procedure proved to be accurate as false negative studies occurred in three of the four bone scans, six of the seven plain radiographs, and three of the four CT scans (the fourth CT scan was reported as equivocal).

\section{Discussion}

Traditionally, the diagnosis of discitis has been established by radiographic or microbiological criteria. We have shown that scintigraphy has an important role in the diagnosis, particularly after more than two weeks of symptoms. The scintigraphic criterion for discitis previously reported is a marked increase in uptake in the vertebral bodies adjacent to the affected disc. ${ }^{3-5}$ Our review confirms this diagnostic appearance and shows that bone scintigraphy is a good indicator of discitis, comparing favourably with other imaging techniques. SPECT imaging increases diagnostic confidence by allowing more accurate localisation of the infected site.

In equivocal cases when conventional radiography and bone scan are not diagnostic for discitis, alternative scintigraphic techniques, such as gallium-67 scanning, can be used to increase diagnostic sensitivity. For example, in case 3 the bone scan was reported as showing possible discitis and this was confirmed with concurrent gallium-67 citrate imaging.

Scintigraphy is easy to perform, non-invasive, and generally available to most clinicians. In view of the possible life threatening consequences of discitis we feel that its early detection and treatment are important and therefore these techniques should be used.

1 Kemp H B S, Jackson J W, Jeremiah J D, Hall A J. Pyogenic infections occurring primarily in intervertebral discs. f Bone foint Surg [Br] 1973; 55: 698-714.

2 McCain G A, Harth M, Bell D A, Disney T F, Austin T, Ralph E. Septic discitis. $\mathcal{F}$ Rheumatol 1981; 8: 100-9.

3 Atkinson R N, Paterson D C, Morris L L, Savage I P. Bone scintigraphy in discitis and related disorders in children. Aust NZ F Surg 1978; 48: 374-7.

4 Goldman A B, Freiberger R H. Localised infectious and neuropathic diseases. Semin Roentgenol 1979; 14: 19-32. Sty J R, Wells R G, Smith W B. The child with acute leg pain. Semin Nucl Med 1988; 18: 137-58. 